\title{
Combustion and Ignition of Thermally Cracked Kerosene in Supersonic Model Combustors
}

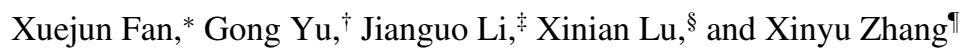 \\ Chinese Academy of Sciences, 100080 Beijing, People’s Republic of China \\ and \\ Chih-Jen Sung** \\ Case Western Reserve University, Cleveland, Ohio 44106
}

\section{DOI: $\underline{10.2514 / 1.26402}$}

\begin{abstract}
A series of experiments were conducted to characterize the self-ignition and combustion of thermally cracked kerosene in both a Mach 2.5 model combustor with a combustor entrance height of $51 \mathrm{~mm}$ and a Mach 3.0 model combustor with an entrance height of $70 \mathrm{~mm}$. A unique kerosene heating and delivery system was developed, which can prepare heated kerosene up to $950 \mathrm{~K}$ at a pressure of $5.5 \mathrm{MPa}$ with negligible fuel coking. The extent of China no. 3 kerosene conversion under supercritical conditions was measured using a specially designed system. The compositions of gaseous products as a result of thermal cracking were analyzed using gas chromatography. The mass flow rates of cracked kerosene were also calibrated and measured using sonic nozzles. With the injection of thermally cracked kerosene, the ability to achieve enhanced combustion performance was demonstrated under a variety of airflow and fuel conditions. Furthermore, self-ignition tests of cracked kerosene in a Mach 2.5 model combustor over a range of fuel injection conditions and with the help of different amounts of pilot hydrogen were conducted and discussed.
\end{abstract}

\section{Introduction}

A SCRAMJET operation at hypersonic speeds places severe cooling requirements on the engine structure. To limit the weight of the cooling system, regenerative cooling using onboard hydrocarbon fuel as the primary coolant is considered to be an effective way for the thermal management. Although the sensible heat of hydrocarbon fuel can meet the cooling requirements up to Mach 5-6, for higher Mach numbers additional cooling can be obtained by increasing the heat sink capacity of hydrocarbon fuel through endothermic reactions [1-4]. Among various endothermic reactions, the thermal cracking of hydrocarbons is the simplest type for practical applications.

Thermal cracking of hydrocarbon fuels has been studied by numerous researchers [1,5-11]. Some important results are highlighted as follows. For the reactions to be endothermic, the preferred products resulting from cracking are mainly olefins such as ethylene, rather than thermodynamically favored, saturated hydrocarbons such as methane and ethane (and coke). However, olefins are not the predominant gaseous products at high pressures. It was also noted that the endothermicity of thermal cracking reactions ( $\sim 700 \mathrm{~kJ} / \mathrm{kg}$ for JP-7 fuel) is much less than the theoretical value by assuming $100 \%$ ethylene formation $(\sim 3500 \mathrm{~kJ} / \mathrm{kg}$ for JP-7 fuel).

There are a number of practical issues related to thermal cracking of hydrocarbon fuels that were not considered in the above-

Presented as Paper 3714 at the 41st AIAA/ASME/SAE/ASEE Joint Propulsion Conference and Exhibit, Tucson, Arizona, 10-13 July 2005; received 8 July 2006; revision received 23 November 2006; accepted for publication 24 November 2006. Copyright $\odot 2006$ by the American Institute of Aeronautics and Astronautics, Inc. All rights reserved. Copies of this paper may be made for personal or internal use, on condition that the copier pay the $\$ 10.00$ per-copy fee to the Copyright Clearance Center, Inc., 222 Rosewood Drive, Danvers, MA 01923; include the code 0748-4658/07 \$10.00 in correspondence with the CCC.

*Associate Professor, Institute of Mechanics, 15 Beisihuanxi Road, Haidian District; xfan@imech.ac.cn. Member AIAA.

†Professor, Institute of Mechanics; yugong @imech.ac.cn. Member AIAA.

\#Professor, Institute of Mechanics; jgli@imech.ac.cn. Member AIAA.

§Professor, Institute of Mechanics; xnlu@imech.ac.cn.

†Professor, Institute of Mechanics; changxy@imech.ac.cn. Member AIAA.

**Associate Professor, Department of Mechanical and Aerospace Engineering; cjs15@ case.edu. Associate Fellow AIAA. mentioned kinetics studies, including the influences of much larger fuel flow rates or much higher Reynolds numbers and the role of heater passage geometries. In addition, because the larger liquid parent fuel decomposes into smaller gaseous hydrocarbons at high temperatures, it is anticipated that these changes in the fuel state or chemical composition will significantly alter the fuel injection behavior and the subsequent ignition and combustion processes [12]. Also, the concentration level of radicals present in the thermally cracked product mixture at high temperatures needs to be quantified because of their important role in facilitating ignition. In view of a limited number of studies in these aspects $[\underline{1}, 13-18]$, a systematic experimental and computational investigation was therefore planned and conducted to address several pertinent issues of fundamental and practical significance.

Our previous experimental investigation [19] on the injection and combustion of vaporized/supercritical kerosene in a Mach 2.5 model combustor demonstrated that the use of vaporized/supercritical kerosene injection holds the potential of enhancing fuel-air mixing and promoting overall burning. It was also noticed that the injection behavior of vaporized/supercritical kerosene differs significantly from that of liquid kerosene due to the changes in temperature and density [19]. In this earlier study, the extent of kerosene cracking is considered to be negligible because the preheat temperature is lower than the critical value for thermal decomposition. Hence, this investigation aims to extend our previous endeavors on the investigation of supersonic combustion using vaporized/supercritical fuel injection to characterize the combustor performance with thermally cracked kerosene injection.

To achieve thermal cracking of kerosene, the existing two-stage heater employed in [19] was upgraded to operate at a higher maximum temperature of $\sim 950 \mathrm{~K}$ and at a peak fuel pressure of 5.5 MPa, while still keeping the amount of fuel coking minimal. A special two-phase flow collection system was also designed to determine the overall conversion of parent kerosene and measure the mass flow rate of cracked kerosene. The composition of the gaseous products from kerosene cracking was further analyzed with gas chromatography. Subsequently, combustion of thermally cracked kerosene was investigated in two model combustors-a Mach 2.5 one with a combustor entrance height of $51 \mathrm{~mm}$ and a Mach 3.0 one with an entrance height of $70 \mathrm{~mm}$. Comparison of combustor performance with different fuel injection modes and airflow conditions were carried out. 
The effect of thermal cracking on self-ignition is also of particular interest. Our previous study [20] demonstrated that self-ignition of liquid kerosene in a Mach 2.5 model combustor can be achieved with the aid of pilot hydrogen injected at an effective hydrogen equivalence ratio of 0.02 or higher. Because the thermally cracked kerosene contains small molecules and radicals, it is imperative to investigate how these composition changes affect the self-ignition limit and the associated combustion characteristics in supersonic model combustors. Thus, self-ignition tests of cracked kerosene in a Mach 2.5 model combustor with a range of fuel injection conditions and varying amounts of pilot hydrogen were also conducted and discussed.

\section{Experimental Specifications}

\section{Test Facility}

The experiments were conducted in both Mach 2.5 and Mach 3.0 test facilities. The Mach 2.5 facility was the same as the one used in [19], and hence will not be described herein. The Mach 3.0 facility consisted of a vitiated air supply system, a multipurpose supersonic model combustor, and a kerosene delivery and heating system. The facility operation, control, and data acquisition were accomplished with a computer. The air supply system was capable of supplying heated air at stagnation temperatures of $800-2100 \mathrm{~K}$ and stagnation pressures of 0.7-2.5 MPa. The Mach 3.0 model combustor shown in Fig. 1 had a total length of $1105.5 \mathrm{~mm}$ and was composed of three sections, including one nearly constant area section with a cross section of $70 \mathrm{~mm}$ in height and $51 \mathrm{~mm}$ in width and two divergent sections. Two interchangeable integrated fuel injector/flameholder cavity modules in tandem were installed on both sides of the combustor, each with a depth of $12 \mathrm{~mm}$, a 45-deg aft ramp angle, and an overall length-to-depth ratio of 7.3. In each module, there were nine (five) orifices of $0.9 \mathrm{~mm}(0.5 \mathrm{~mm})$ diameter designed for vaporized (liquid) kerosene injection, while there were five orifices of $1.0 \mathrm{~mm}$ diameter available for pilot hydrogen injection. Kerosene and pilot hydrogen were injected normally to the airflow through the cavity floor and just ahead of the cavity, respectively, as shown in Fig. 1 .
Stagnation pressure and stagnation temperature of vitiated air ware measured using a CYB-10S pressure transducer and a type B thermocouple, respectively. Static pressure distribution in the axial direction was determined using Motorola MPX2200 pressure transducers installed along the centerline of the model combustor sidewalls. The experimental uncertainty in the pressure and temperature measurements was within $3 \%$.

The entire test facility was mounted upright on a platform and can be translated laterally and vertically. It usually took approximately $2.5 \mathrm{~s}$ to establish a steady Mach 3.0 airflow and a typical run lasted around $7 \mathrm{~s}$.

\section{Kerosene Delivery and Heating System}

To minimize the fuel coking at high temperature, a two-stage heating system shown in Fig. 2 was specially designed. The first stage was a storage-type heater that can heat kerosene of $0.8 \mathrm{~kg}$ up to $570 \mathrm{~K}$ in approximately $10 \mathrm{~min}$ with negligible coking deposits. The second stage heater was a continuous type, which was capable of rapidly heating kerosene to $950 \mathrm{~K}$. Although the residence time of heated kerosene within the second stage heater was typically less than $4 \mathrm{~s}$, the extent of fuel coking was minimized. Furthermore, the first stage heater was composed of a 20-m long stainless steel tube of $20 \mathrm{~mm}$ outer diameter and $1.5 \mathrm{~mm}$ wall thickness, which was wound into a cylinder shape of $30 \mathrm{~cm}$ diameter. The stainless steel tube was wrapped with five 960-W heating tapes, which were controlled independently to achieve a uniform temperature distribution along the tube. The second stage heater was made of a hollow stainless steel tube of $16 \mathrm{~mm}$ outer diameter and $2 \mathrm{~mm}$ wall thickness. The total length of the second stage heating tube was approximately $23.5 \mathrm{~m}$. To rapidly raise the preheat temperature, the second stage heater was resistively heated by directly passing a current through the stainless steel tube at $80-100$ dc voltages from a pulsed ac/dc welder power supply of $25 \mathrm{KW}$.

Before the experiments, kerosene in a storage cylinder was pumped into the first stage heater by a piston. Two pneumatic valves (Swagelok, model nos. SS6UM and SS10UM) installed, respectively, at the exits of the first and the second stage heaters were employed to turn on/off the two heaters sequentially, as shown

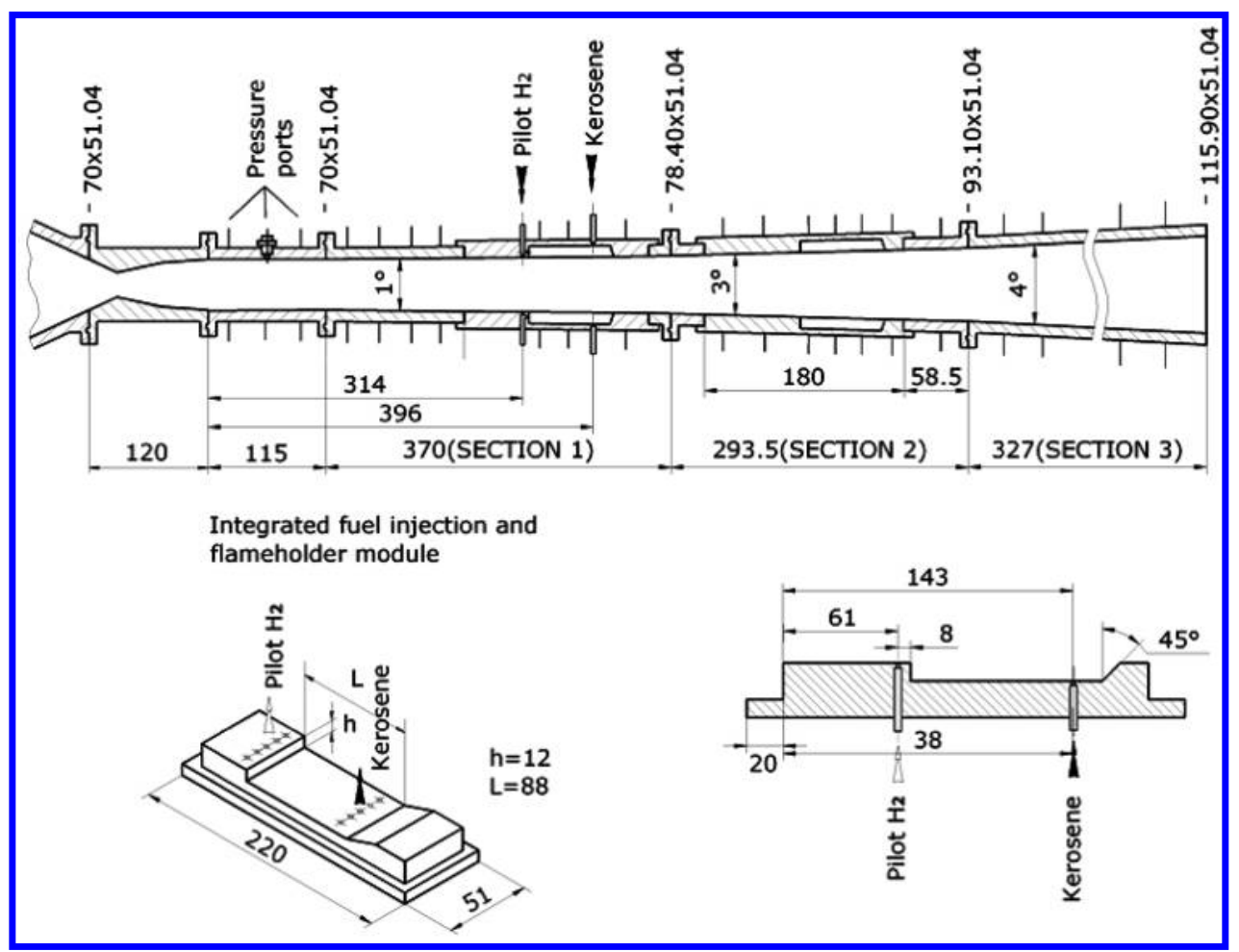

Fig. 1 Schematic of kerosene/pilot hydrogen Mach 3.0 model combustor (top) and integrated fuel injection and flameholder module (bottom). All length dimensions are in $\mathbf{m m}$. 


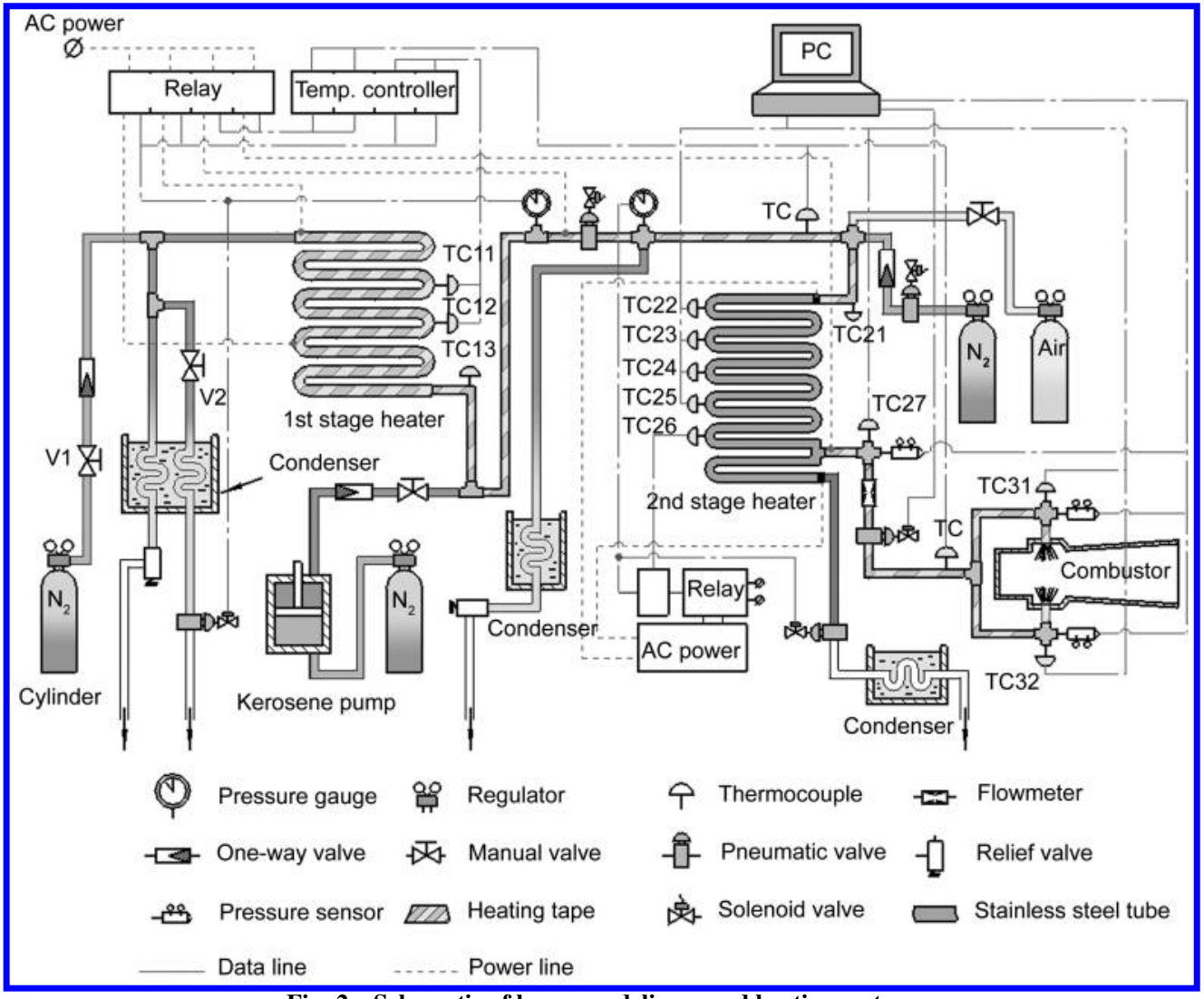

Fig. 2 Schematic of kerosene delivery and heating system.

in Fig. 2. When kerosene in the first stage heater reached a desired temperature at high pressure, kerosene was pressed into the second stage heater and heated up to the working temperature before being injected into the combustor. After each run, air was used to purge out the residual kerosene inside the second stage heater and to eliminate any accumulation of carbon deposit. Two groups of K-type thermocouples (Omega, model no. KMQSS-0.032E), TC11-13 and TC21-26 shown in Fig. 2, were installed on the surface of or inserted into the heater tubes and were used to monitor and achieve the feedback control of fuel temperature distribution along the heating system. The experimental uncertainty in fuel temperature measurements was estimated to be $2 \%$.

In addition, the second stage heater and the fuel injectors were connected by $10 \mathrm{~mm}$ diameter tubes, which were also wrapped by heating tapes and heated up to a temperature close to that of the second stage heater to reduce heat loss and avoid kerosene condensation before reaching the injectors. To minimize the heat loss of kerosene vapor or cracked fuel mixture to the flameholder module, the design of kerosene injectors was modified from our earlier setup.

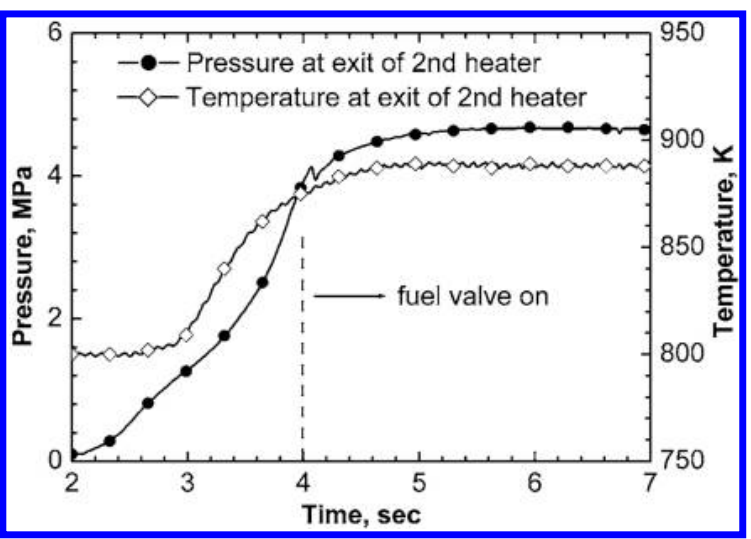

Fig. 3 Time histories of fuel temperature and pressure measured at the exit of the second stage heater.
Specifically, instead of drilling orifices directly in the typical cavity floor of $\sim 33 \mathrm{~mm}$ thickness, the kerosene injection station was composed of small diameter tubes, $2 \mathrm{~mm}$ inside diameter and $1 \mathrm{~mm}$ wall thickness, which were welded to a much thinner plate of $3 \mathrm{~mm}$ thickness. These injection tubes were also wrapped with heating tapes and were heated before each test run. The maximum preheat temperature achievable was approximately $930 \mathrm{~K}$. Each fuel injection temperature $\left(T_{\text {in }}\right)$ reported herein was based on a thermocouple spot welded on the tube surface.

Much effort was also devoted to establishing a quick delivery of the heated/cracked kerosene with stable fuel temperature and pressure. Figure 3 shows the performance of the two-stage heating system by plotting the time variations of temperature and pressure of the cracked kerosene at the exit of the second stage heater. In this case, the pneumatic valve between the first and the second stage heaters was turned on at a reference time of $2 \mathrm{~s}$, and the fuel injection started at a reference time of $4 \mathrm{~s}$. It is seen from Fig. 3 that the fuel temperature and pressure profiles leveled off in about $2 \mathrm{~s}$ after turning on the pneumatic valve and were kept almost constant during the experiment duration.

\section{Kerosene Conversion and Flow Rate Measurement System}

Our previous investigation [19] has demonstrated that the mass flow rate of vaporized and supercritical kerosene can be calibrated and measured using a sonic nozzle as long as there is no condensation during flow acceleration and the sonic condition is maintained at the nozzle throat. In the cases of thermally cracked kerosene, no simple dependence of the mass flow rate on fuel temperature and pressure would be expected because the fuel composition changes dramatically during cracking and the extent of conversion also depends on the heating history and the mass flow rate itself. However, for a given heater configuration (with consistent temperature distribution along the heater) and a narrow range of operational conditions, it is practical to assume that the final composition of cracked fuel would remain approximately the same for the same temperature and pressure such that a sonic nozzle would give a consistent measurement of the mass flow rate. Modifications 


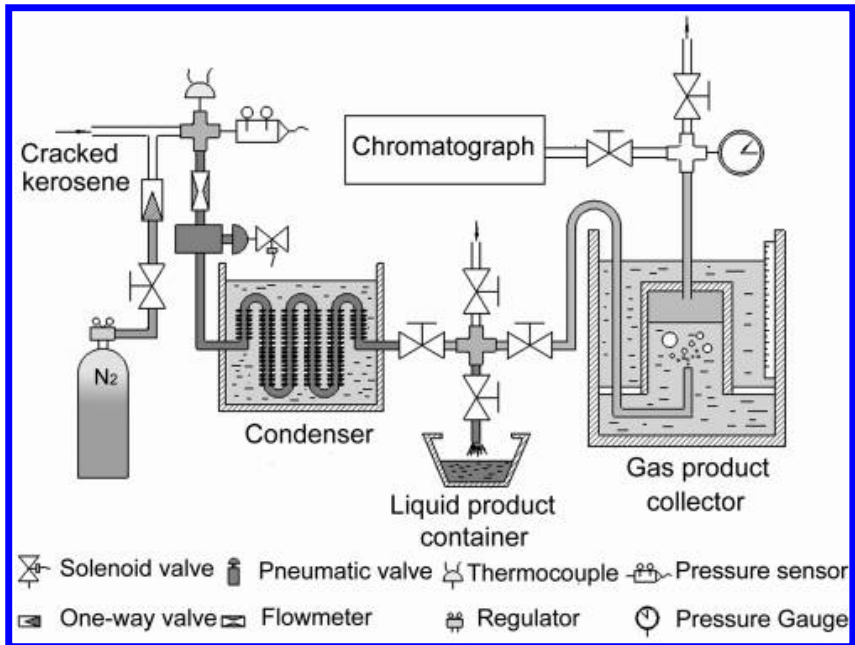

Fig. 4 Schematic of product collection/analysis and flow rate measurement system.

of the existing calibration system are also required because the cracked fuel mixture would undergo phase changes when cooled down to the ambient temperature. As a result, the unreacted kerosene and the heavier cracking products $\left(>\mathrm{C}_{5}\right)$ condensed to liquid products, while the lighter products $\left(\mathrm{C}_{1}-\mathrm{C}_{5}\right)$ turned into gaseous products.

Figure 4 shows the schematic of the present product collection and flow rate calibration system. The mass flow rate of cracked kerosene was measured using a sonic nozzle installed at the exit of the second stage heater. After passing through the sonic nozzle, the cracked fuel mixture was cooled to room temperature using an air-conditioner condenser circulated with cold water. The liquid products and carbon deposits (if present) were collected directly after cooling, while the gaseous products were collected using a container immersed in a water pool and its volume was measured by the volume of water displaced. The composition of gaseous product mixture was analyzed using gas chromatography, and its average molecular weight and density were determined. The mass flow rate was determined from the total mass of collected liquid and gaseous products divided by the time duration of fuel discharging, which was precisely controlled by the pneumatic valves through a computer. Because of the large variation of kerosene density in the temperature range of 570-920 K, four different throat diameters, including 2.15, $2.5,3.08$, and $3.4 \mathrm{~mm}$, were used to meet the mass flow rate requirements for the subsequent combustion experiments. Considering the measurement accuracies of throat area, fuel pressure, and fuel temperature, the overall uncertainty associated with the measured fuel mass flow rate was within $5 \%$.

Because kerosene is composed of a myriad of individual components, it is very difficult to define the actual percentage of kerosene decomposition without knowing the concentration change of each component during thermal cracking. Edwards and Anderson [9] defined a JP-7 conversion to gas over a certain period of time simply based on the volume change of liquid parent fuel. As discussed above, the total mass of liquid products $\left(m_{L}\right)$ and the total mass of gaseous products $\left(m_{g}\right)$ were measured in the present study. If all of the liquid products collected were treated as unreacted kerosene, the mass fraction of kerosene conversion to gaseous products can be defined as $m_{g} /\left(m_{g}+m_{L}\right)$. In addition, a nominal mole fraction of gas products was defined as

$$
\chi_{g}=\frac{m_{g} / \varpi_{g}}{m_{g} / \varpi_{g}+m_{L} / \varpi_{k}}
$$

where $\varpi_{k}$ and $\varpi_{g}$ are the measured average molecular weights of kerosene and the gas products, respectively. This nominal mole fraction together with the mass fraction of gas products was used herein to characterize the extent of kerosene conversion.

\section{Results and Discussion}

Measurements of Kerosene Conversion and Mass Flow Rate

A conventional jet fuel, China no. 3 aviation kerosene, was employed in this study. On the volume basis, it is approximately composed of $92.5 \%$ saturated hydrocarbons, $0.5 \%$ unsaturated hydrocarbons, and $7 \%$ aromatic hydrocarbons. The overall chemical formula of this kerosene is approximately $\mathrm{C}_{11} \mathrm{H}_{22}$. Using the calibration system shown in Fig. $\underline{4}$, the liquid and gaseous products from thermal cracking of China no. 3 kerosene were separated and analyzed. With a fuel pressure of $5.5 \mathrm{MPa}$, Fig. $\underline{5}$ shows and compares the measured composition of gaseous products at four different fuel temperatures. The primary gaseous products obtained were alkanes and alkenes of small carbon number $\left(C_{1}-C_{5}\right)$, and had an averaged molecular weight of $26-30$. For the conditions tested, no hydrogen was detected. Figure 5 also indicates $25-45 \%$ (by mole) of methane present in the gaseous products and a trend toward greater kerosene conversion to methane with increasing temperature. However, such a large molar percentage of methane found in the gaseous product mixture represents a low chemical heat sink available through the thermal cracking of kerosene.

Figure 6 plots the measured nominal mole fraction of gaseous products $\left(\bar{\chi}_{g}\right)$ at varying fuel temperatures. The measurements were carried out at fuel pressures of 3.5-5.0 MPa and fuel mass flow rates of $20-80 \mathrm{~g} / \mathrm{s}$. It is seen from Fig. 6 that for the conditions tested the extent of kerosene conversion can be correlated quite well with fuel temperature alone, indicating a strong dependence of $\chi_{g}$ on fuel temperature, but relatively weak dependences on fuel pressure and mass flow rate.

Figure 7 shows the measured mass flow rates per unit throat area for kerosene of different temperatures. As mentioned earlier, four

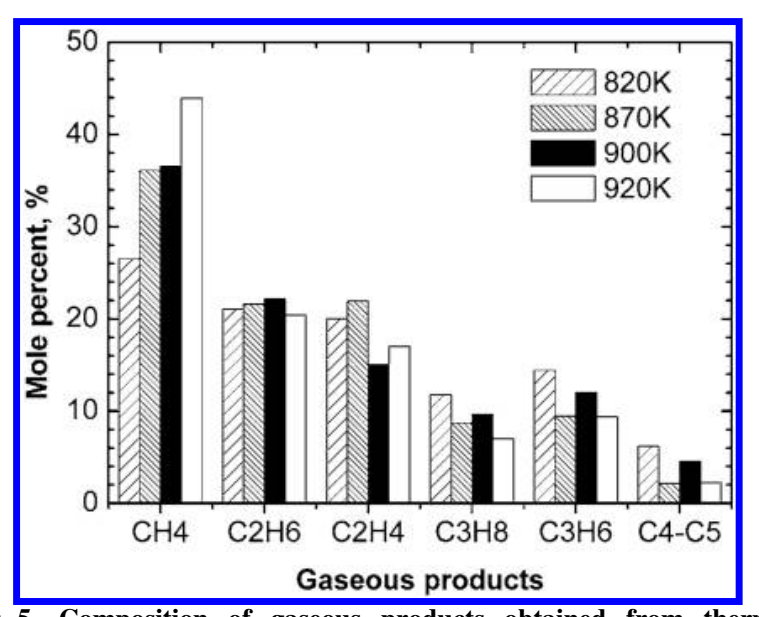

Fig. 5 Composition of gaseous products obtained from thermal cracking of China no. 3 kerosene at varying fuel temperatures.

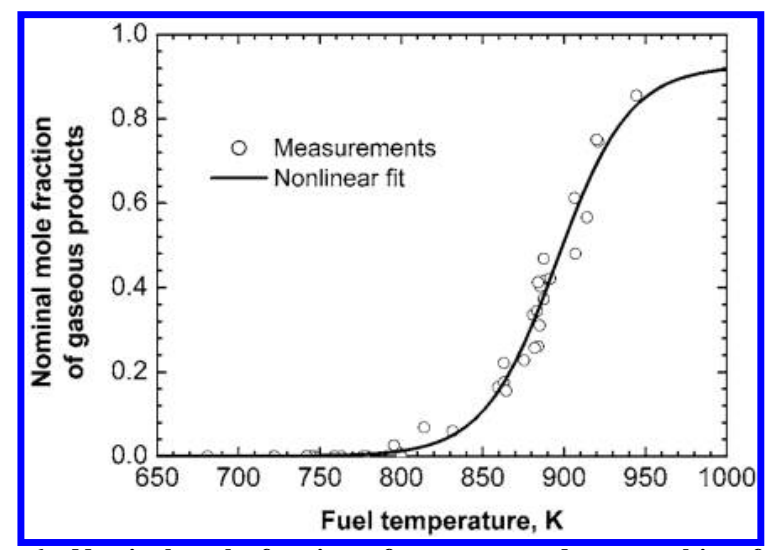

Fig. 6 Nominal mole fraction of gaseous products resulting from thermal cracking of China no. 3 kerosene as a function of fuel temperature. 


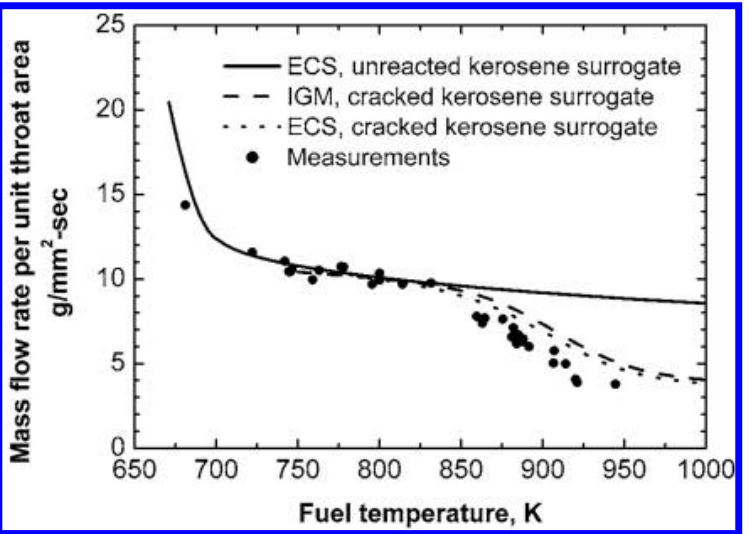

Fig. 7 Comparison of measured mass flow rates per unit throat area and calculated values of unreacted kerosene surrogate and cracked kerosene using the models of extended corresponding states (ECS) and ideal gas mixture (IGM). All the experimental and computational values were based on a reference fuel pressure of 3.5 MPa.

sonic nozzles of difference throat areas were used over the present flow rate range. Although a range of fuel pressures was used in the experiments, the values of mass flow rate per unit throat area plotted in Fig. 7 were converted to those based on a reference pressure of $3.5 \mathrm{MPa}$ by assuming that the mass flow rate per unit throat area is proportional to fuel pressure (in the region not close to a critical point). The use of a reference fuel pressure also facilitates the comparison with the computed values using different theoretical models. It is seen from Fig. 7 that the measured mass flow rate per unit throat area decreases with increasing fuel temperature, with a sudden reduction occurring near $850 \mathrm{~K}$. This temperature corresponds well to the critical value beyond which a substantial amount of kerosene is decomposed, as shown in Fig. 6.

The measured mass flow rates per unit throat area are also compared with the theoretical values using surrogate fuels. A kerosene surrogate that closely matches the average molecular weight and $\mathrm{C} / \mathrm{H}$ ratio of the China no. 3 kerosene was chosen, based on the surrogate proposed by Dagaut [21]. Table 1 lists the composition of this kerosene surrogate. According to the composition analysis shown in Fig. 5, a surrogate representing the gaseous products resulting from the thermal cracking of kerosene was used, as listed in Table 2 . As such, when considering a cracked kerosene mixture for a given fuel temperature in calculations, the mixture composition, a blend of two surrogates shown in Tables 1 and 2 , was determined with the empirical value of $\chi_{g}$ obtained from

Table 1 Composition of China no. 3 aviation kerosene surrogate

\begin{tabular}{lc}
\hline \hline Hydrocarbons & Mole fraction \\
\hline$n$-dodecane & 0.63 \\
$1,3,5$-trimethylcyclohexane & 0.30 \\
$n$-propylbenzene & 0.07 \\
Average molecular weight & 152 \\
Average chemical formula & $\mathrm{C}_{10.9} \mathrm{H}_{21.3}$ \\
\hline \hline
\end{tabular}

Table 2 Surrogate composition of the gaseous products resulting from thermal cracking

\begin{tabular}{lc}
\hline \hline Hydrocarbons & Mole fraction \\
\hline Methane, $\mathrm{CH}_{4}$ & 0.35 \\
Ethane, $\mathrm{C}_{2} \mathrm{H}_{6}$ & 0.20 \\
Propane, $\mathrm{C}_{3} \mathrm{H}_{8}$ & 0.15 \\
Ethylene, $\mathrm{C}_{2} \mathrm{H}_{4}$ & 0.15 \\
Propylene, $\mathrm{C}_{3} \mathrm{H}_{6}$ & 0.15 \\
Average molecular weight & 28.7 \\
Average chemical formula & $\mathrm{C}_{1.95} \mathrm{H}_{5.3}$ \\
\hline \hline
\end{tabular}

Fig. 6. Furthermore, computational results compared in Fig. 7 were based on two models, the model of extended corresponding states (ECS) [22] and the model of ideal gas mixture (IGM), along with a discharge coefficient of 0.91 for the sonic nozzle calculations.

Consistent with our previous findings [19], Fig. 7 demonstrates that the ECS calculations using the unreacted kerosene surrogate agree well with the experimental results for fuel temperatures below $830 \mathrm{~K}$, because of insignificant kerosene cracking. When fuel temperature increases beyond $830 \mathrm{~K}$, a large discrepancy is noted in Fig. 7 for calculations without considering thermal cracking of kerosene, while agreement with experiments improves when including the corresponding cracked kerosene surrogate mixture. It is also seen from Fig. 7 that for fuel temperatures higher than $800 \mathrm{~K}$, both the ECS and IGM calculations for the cracked kerosene mixture yield very close results. However, both calculations overpredict the measured values by approximately $30 \%$ for fuel temperatures higher than $830 \mathrm{~K}$. It was further found that the measured mass flow rate could be well predicted by using a much lower mean molecular weight for the cracked fuel mixture. Because the sonic nozzle was installed at the exit of the second stage heater (cf. Fig. 4), this in turns implies that a substantial amount of low molecular weight, unstable species, such as hydrocarbon fragments, may be present at high temperatures, which, however, cannot be determined using gas chromatography. Further study is needed to accurately characterize the composition of the cracked kerosene mixture.

\section{Combustion Characteristics of Thermally Cracked Kerosene}

A series of combustion experiments using thermally cracked kerosene injection were first conducted in the same Mach 2.5 model combustor as our early study [19] to compare the combustion performance with those with liquid and supercritical kerosene injection. The height of the combustor entrance for this model combustor was $51 \mathrm{~mm}$. All experiments were conducted under approximately identical flow conditions: a stagnation temperature of $\sim 1750 \mathrm{~K}$ and a stagnation pressure of $\sim 1.15 \mathrm{MPa}$. To facilitate the self-ignition of kerosene in this model combustor, the same amount of pilot hydrogen was used in these tests. Figure 8 compares the static pressure profiles along the axial direction in the Mach 2.5 model combustor for the three fuel injection modes at constant fuel mass flow rates of $\sim 37 \mathrm{~g} / \mathrm{s}$. The relative locations of kerosene injection, pilot hydrogen injection, and cavity flameholder are also sketched in Fig. 8. For the combustion tests of liquid kerosene, the fuel was injected at room temperature and under injection pressure of $\sim 1.9 \mathrm{MPa}$. For the supercritical kerosene injection mode, the fuel before injection was preheated to a temperature of $\sim 730 \mathrm{~K}$, under a supercritical pressure of $\sim 3.8 \mathrm{MPa}$. In the combustion experiments using cracked kerosene, the fuel was preheated to $815-886 \mathrm{~K}$, under pressures of 3.1-4.25 $\mathrm{MPa}$. Note that the mass percentages of

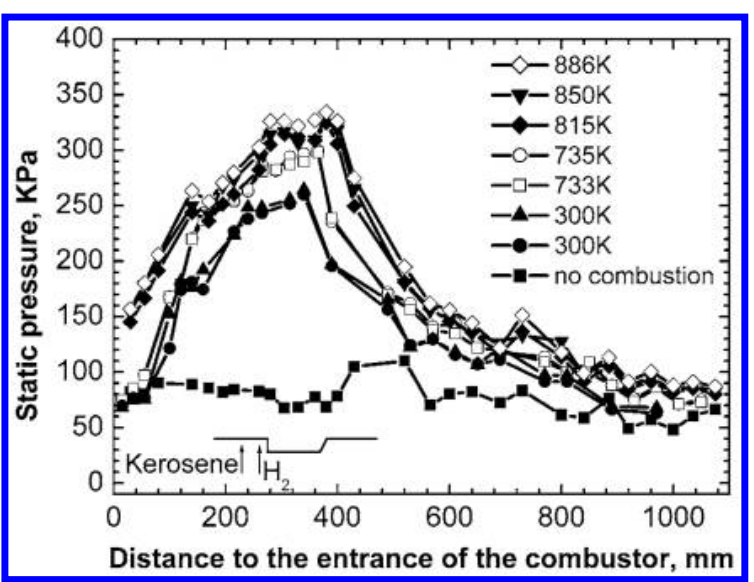

Fig. 8 Comparison of static pressure distributions with liquid, supercritical, and cracked kerosene injections in the Mach 2.5 model combustor with the combustor entrance height of $51 \mathrm{~mm}$. Fuel mass flow rate was $\sim 37 \mathrm{~g} / \mathrm{s}$. Vitiated air: stagnation temperature was $\sim 1750 \mathrm{~K}$ and stagnation pressure was $1.15 \mathrm{MPa}$. 


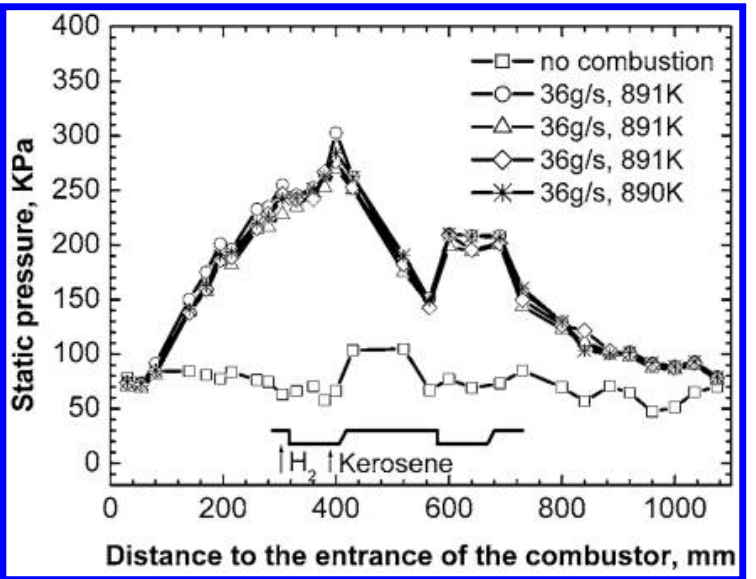

Fig. 9 Comparison of static pressure distributions from four different combustion runs in the Mach $\mathbf{2 . 5}$ model combustor under approximately identical airflow and fuel injection conditions. Vitiated air: stagnation temperature was $\sim 1720 \mathrm{~K}$ and stagnation pressure was $\sim 1.11 \mathrm{MPa}$.

kerosene conversion to gaseous products were $5-15 \%$ in this fuel temperature range. It can be seen from Fig. 8 that the overall pressure level during combustion increased significantly by changing the injection mode from liquid kerosene to supercritical kerosene, and continued to increase when transitioning to the cracked kerosene injection mode. However, for the combustion tests using cracked kerosene the static pressure increase was observed to commence even within the isolator section.

To demonstrate the reproducibility of the present experiments using cracked kerosene injection, Fig. 9 compares the measured static pressure distributions in the Mach $\overline{2} .5$ model combustor from four different runs under approximately identical airflow and fuel injection conditions. It is noted in Fig. 9 that the fuel injection location is now at the floor of the first cavity flameholder and is moved more downstream as compared to that of Fig. 8. As a consequence, the undesired pressure rise near the combustor entrance at a higher fuel flow rate or a higher fuel temperature was shown to be mitigated. Figure 9 clearly demonstrates that the present experimental data were highly repeatable with an uncertainty of $\sim 3 \%$.

Recognizing that the combustor geometry and the entry Mach number play important roles in affecting combustor performance, a series of experiments were also carried out in a Mach 3.0 model combustor with a larger entrance height of $70 \mathrm{~mm}$, as shown in Fig. 1 . To compensate the possible decreases in the fuel-air mixing levē and combustion stability due to increased Mach number and entrance height, two cavities in tandem were used instead of a single cavity. Comparison of the combustor performance using the two types of cavity arrangement was conducted first. The kerosene was preheated to a temperature of $\sim 910 \mathrm{~K}$ under pressure of $\sim 4.8 \mathrm{MPa}$ before being injected into the combustor at a mass flow rate of $\sim 53 \mathrm{~g} / \mathrm{s}$. With the same airflow and injection conditions, Fig. 10 demonstrates that the overall pressure level near the fuel injection location is higher when using two cavities in tandem. This higher pressure level in turns implies a higher burning intensity. However, the addition of a second cavity (without fuel injection therein) is expected to increase the downstream combustor drag. Further investigation is therefore warranted to elucidate whether the configuration of two cavities in tandem indeed provides enough benefit to overcome the drag penalty.

We further note that for a given throat diameter of the sonic nozzle flow meter, a higher fuel pressure is required for a higher fuel temperature to keep the fuel mass flow rate constant. Hence, the effect of fuel pressure on combustor performance needs to be clarified. For this purpose, additional combustion tests using a cracked kerosene mixture with mass flow rate of $\sim 55 \mathrm{~g} / \mathrm{s}$ and temperature of $\sim 870 \mathrm{~K}$ were carried out. To vary the fuel pressure while keeping the same mass flow rate and fuel temperature, two different sonic nozzles with throat diameters of 2.5 and $3.08 \mathrm{~mm}$

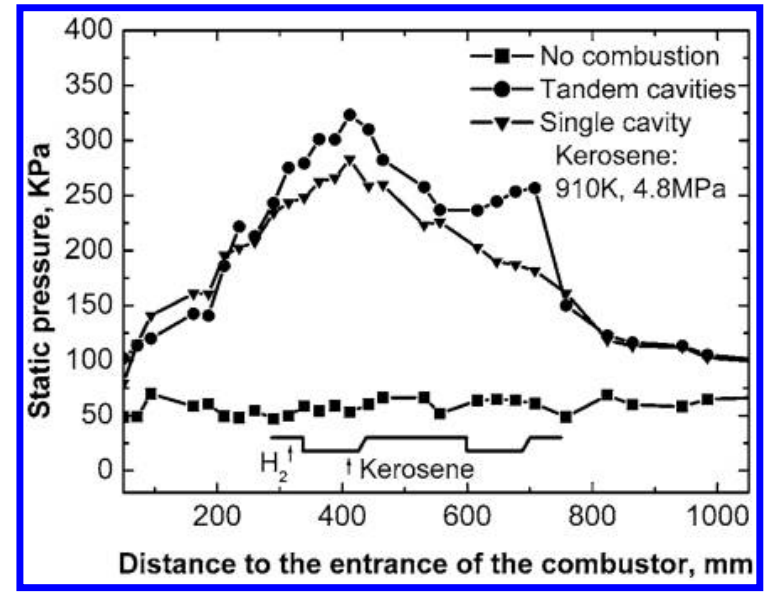

Fig. 10 Comparison of static pressure distributions with single cavity and two cavities in tandem in the Mach 3.0 model combustor with combustor entrance height of $\mathbf{7 0} \mathbf{~ m m}$ under approximately identical airflow and fuel injection conditions. Vitiated air: stagnation temperature was $\sim 1850 \mathrm{~K}$ and stagnation pressure was $\sim 1.9 \mathrm{MPa}$.

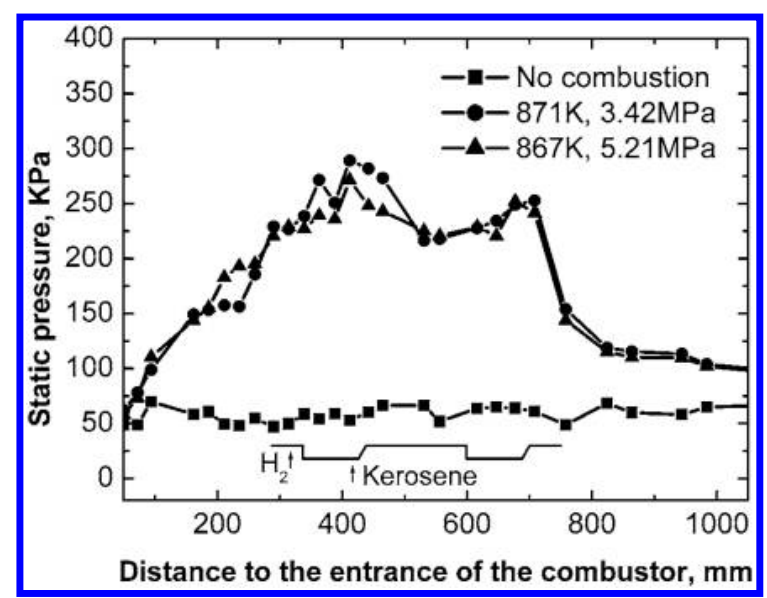

Fig. 11 Comparison of static pressure distributions with cracked kerosene injection at two different fuel pressures in the Mach 3.0 model combustor. Vitiated air: stagnation temperature was $\sim 1860 \mathrm{~K}$ and stagnation pressure was $\sim 1.9 \mathrm{MPa}$.

were used. Figure 11 plots such a comparison for two fuel pressures of 3.42 and $5.21 \overline{\mathrm{MP}}$ a, showing that the two static pressure profiles match with each other closely. This comparison suggests that the fuel injection pressure had a much less effect on the combustion characteristics of cracked kerosene than the fuel temperature did (also cf. Fig. 8), at least for the fuel pressure range investigated. Therefore, combustion of thermally cracked kerosene was further investigated in the Mach 3.0 model combustor with special emphasis on its dependence on fuel temperature or the extent of kerosene conversion, which is discussed in the following.

Figure 12 compares the static pressure profiles in the Mach 3.0 combustor with increasing fuel temperature. The airflow conditions were kept approximately identical, at a stagnation temperature of $\sim 1880 \mathrm{~K}$, a stagnation pressure of $\sim 1.88 \mathrm{MPa}$, and a mass flow rate of $\sim 1150 \mathrm{~g} / \mathrm{s}$. Moreover, the fuel injection pressures were all higher than the critical pressure of kerosene, and the fuel mass flow rate was around $55 \mathrm{~g} / \mathrm{s}$. Figure 12 clearly shows that the overall pressure level increased dramatically as the fuel temperature was increased from 725 to $911 \mathrm{~K}$. Note that the heated kerosene was in supercritical states at $725 \mathrm{~K}$, while approximately $25 \%$ of the kerosene mass was converted to lower order $\mathrm{C}_{1}-\mathrm{C}_{5}$ hydrocarbons at $911 \mathrm{~K}$. Further analysis using the one-dimensional model developed in an earlier study [23] yielded combustion efficiencies of $85,86,89$, and $94 \%$ for fuel temperatures of $725,839,891$, and $911 \mathrm{~K}$, respectively. Thus, the use of cracked kerosene injection was shown to promote the overall burning intensity. We shall examine in the next section how 


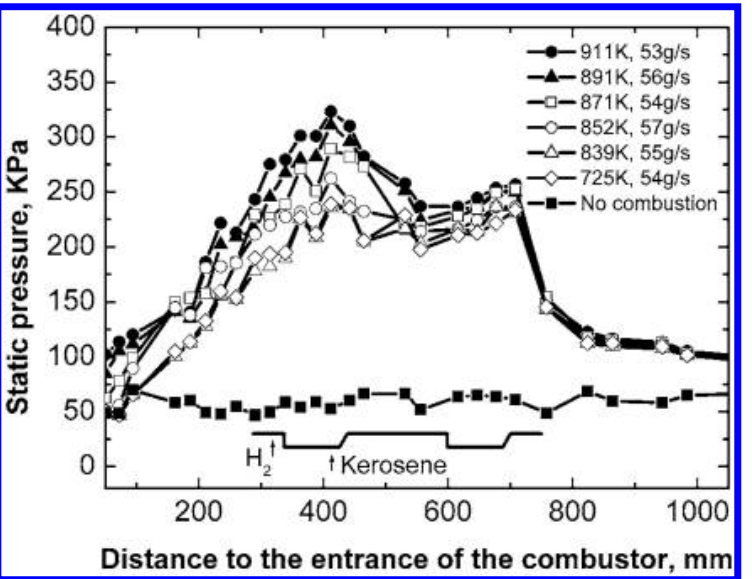

Fig. 12 Comparison of static pressure distributions with kerosene injection at different fuel temperatures in the Mach 3.0 model combustor. Vitiated air: stagnation temperature was $\sim 1880 \mathrm{~K}$ and stagnation pressure was $\sim 1.88 \mathrm{MPa}$.

the thermal cracking of kerosene affects the conditions of selfignition.

\section{Self-Ignition Tests of Thermally Cracked Kerosene in the Mach 2.5 Model Combustor}

A series of self-ignition experiments using thermally cracked kerosene injection were conducted in the same Mach 2.5 model combustor with a single cavity module as used in Fig. 8 . The airflow conditions were kept approximately the same at a stagnation temperature of $\sim 1700 \mathrm{~K}$ and a stagnation pressure of $\sim 1.11 \mathrm{MPa}$. Kerosene was preheated to temperatures of 865-928 K under pressures of $3.75-4.40 \mathrm{MPa}$ before being injected into the combustor. The heat loss of the fuel mixture during injection processes was controlled as described earlier, and hence the fuel injection temperature $\left(T_{\text {in }}\right)$ was fairly close to the preheat fuel temperature.

Table 3 summarizes the test conditions and the corresponding results. Following [20], the equivalence ratio of pilot hydrogen $\left(\phi_{\mathrm{H}}\right)$ and the effective equivalence ratio of kerosene $\left(\phi_{\text {fuel }}\right)$ were defined by assuming that hydrogen is consumed completely with the available oxygen because of its small addition and kerosene is then oxidized with the remaining air. As a reference, our previous investigation of liquid kerosene injection demonstrated that the minimum equivalence ratio of pilot hydrogen required for facilitating the self-ignition of kerosene can be as low as 0.02 for certain combustor configurations [20]. Table $\underline{3}$ shows that, for partially cracked kerosene injection, self-ignition can be achieved even with $\phi_{\mathrm{H}}=0.01$. Furthermore, it is of interest to note from the tests of successful self-ignition that the time interval from turning on the fuel

Table 3 Self-ignition tests of cracked kerosene in the Mach 2.5 model combustor. Vitiated air: stagnation temperature and pressure were approximately $1700 \mathrm{~K}$ and $1.11 \mathrm{MPa}$, respectively. $P_{\text {fuel }}$ denotes the fuel injection pressure. Injection schemes of kerosene and pilot hydrogen are shown in Fig. 8.

\begin{tabular}{lccccc}
\hline \hline Test no. & $P_{\text {fuel }}, \mathrm{MPa}$ & $T_{\text {in }}, \mathrm{K}$ & $\phi_{\text {fuel }}$ & $\phi_{\mathrm{H}}$ & Ignition? \\
\hline $\mathrm{A}$ & 3.75 & 742 & 0.39 & 0.04 & Yes \\
$\mathrm{B}$ & 4.15 & 757 & 0.52 & 0.03 & Yes \\
$\mathrm{C}$ & 4.15 & 733 & 0.44 & 0.03 & Yes \\
D & 3.65 & 755 & 0.37 & 0.02 & Yes \\
E & 3.55 & 738 & 0.37 & 0.01 & No \\
F & 3.92 & 764 & 0.21 & 0.01 & No \\
$\mathrm{G}$ & 3.92 & 884 & 0.26 & 0.01 & No \\
$\mathrm{H}$ & 4.42 & 907 & 0.30 & 0.01 & Yes \\
$\mathrm{I}$ & 4.41 & 915 & 0.31 & 0.01 & Yes \\
J & 4.40 & 931 & 0.29 & 0.01 & Yes \\
K & 4.40 & 920 & 0.34 & 0.0075 & No \\
L & 4.40 & 907 & 0.32 & 0.004 & No \\
\hline \hline
\end{tabular}

valve to the rapid rise of static pressures within the combustor became longer when $\phi_{\mathrm{H}}$ was reduced below 0.02 .

\section{Conclusions}

Combustion characteristics of thermally cracked kerosene were investigated experimentally over a range of airflow and fuel conditions. Cracked kerosene was prepared using a two-stage kerosene heating and delivery system, which was capable of heating kerosene up to $950 \mathrm{~K}$ at a pressure of $5.5 \mathrm{MPa}$ and leading to a maximum $50 \%$ mass conversion of kerosene with negligible fuel coking. Chromatographs of the gaseous products collected from the thermal cracking of China no. 3 kerosene showed a $25-45 \%$ mole percentage of methane formation and a trend toward greater conversion to methane with increasing fuel temperature, indicating that the thermal cracking of kerosene would be less endothermic.

The mass flow rates of cracked kerosene were calibrated and measured using sonic nozzles. Surrogates composed of the representative components of unreacted kerosene and the gaseous products of cracked kerosene were, respectively, chosen to match the corresponding mean molecular weight and $\mathrm{C} / \mathrm{H}$ ratio and were used to theoretically calculate the fuel mass flow rates. Computed mass flow rates based on both the principle of extended corresponding states and the law of ideal gas mixture overpredicted the experimental values of cracked kerosene by approximately $30 \%$, suggesting the possible presence of some lightweight intermediate species in the cracked mixture at high temperatures which were not detected by the gas chromatography analysis.

A series of combustion experiments were conducted in a Mach 2.5 model combustor with an entrance height of $51 \mathrm{~mm}$ and a Mach 3.0 model combustor with an entrance height of $70 \mathrm{~mm}$. Results obtained from both model combustors demonstrated that enhanced burning intensity and higher combustion efficiency were achieved with the injection of thermally cracked kerosene. Self-ignition tests of cracked kerosene with different amounts of pilot hydrogen in a Mach 2.5 model combustor were also conducted and compared over a range of fuel injection conditions. It was generally observed that the amount of pilot hydrogen required for achieving self-ignition decreased with an increasing extent of kerosene cracking.

\section{Acknowledgements}

This research was supported by the Natural Science Foundation of China under Contract no. 10232060. The authors would like to acknowledge the technical support of Ying Li and Xuesong Wei during experiments. The authors would also like to thank Xiangwen Zhang from Tianjin University for gas analyses.

\section{References}

[1] Lander, H., and Nixon, A. C., "Endothermic Fuels for Hypersonic Vehicles," Journal of Aircraft, Vol. 8, No. 4, 1971, pp. 200-207.

-[2] Sobel, D. R., and Spadaccini, L. J., "Hydrocarbon Fuel Cooling Technologies for Advanced Propulsion," Journal of Engineering for Gas Turbines and Power, Vol. 119, No. 2, 1997, pp. 344-351.

[3] Maurice, L., and Edwards, T., "Liquid Hydrocarbon Fuels for Hypersonic Propulsion," Scramjet Propulsion, edited by E. T. Curran, and S. N. B. Murthy, Vol. 189, Progress in Astronautics and Aeronautics, AIAA, Reston, VA, 2001, pp. 757-822.

[4] Edwards, T., "Liquid Fuel and Propellant for Aerospace Propulsion: 1903-2003," Journal of Propulsion and Power, Vol. 19, No. 6, 2003, pp. 1089-1107.

[5] Fabuss, B. M., Smith, J. O., and Satterfield, C. N., "Rapid Thermal Cracking of n-Hexadecane at Elevated Pressures," Industrial and Engineering Chemistry Process Design and Development, Vol. 1, No. 4, 1962, pp. 293-299.

[6] Fabuss, B. M., Smith, J. O., and Satterfield, C. N., "Thermal Cracking of Pure Saturated Hydrocarbons," Advances in Petroleum Chemistry and Refining, edited by J. J. Mcketta, Vol. 9, Wiley, New York, 1964, pp. 157-201.

- [7] Zhou, P., and Crynes, B. L., "Thermolytic Reactions of Dodecane," Industrial and Engineering Chemistry Process Design and Development, Vol. 25, No. 2, 1986, pp. 508-514.

[8] Khorasheh, F., and Murray, R. G., "High-Pressure Thermal Cracking of 
n-Hexadecane," Industrial and Engineering Chemistry Research, Vol. 32, No. 9, 1993, pp. 1853-1863.

[9] Edwards, T., and Anderson, S. D., "Results of High Temperature JP-7 Cracking Assessment," AIAA Paper 93-0806, Jan. 1993.

[10] Ianovski, L., and Sapgir, G., "Heat and Mass Transfer to Hydrocarbon Fuels at Thermal Decomposition in Channels of Engine," AIAA Paper 96-2683, July 1996.

[11] Yu, J., and Eser, S., "Thermal Decomposition of $\mathrm{C}_{10}-\mathrm{C}_{14}$ Normal Alkanes in Near-Critical and Supercritical Regions: Product Distributions and Reaction Mechanisms," Industrial and Engineering Chemistry Research, Vol. 36, No. 3, 1997, pp. 574-584.

[12] Tishkoff, J. M., Drummond, J. P., Edwards, T., and Nejad, A. S., "Future Direction of Supersonic Combustion Research: Air Force/ NASA Workshop on Supersonic Combustion," AIAA Paper 97-1017, Jan. 1997.

[13] Huang, H., Spadaccini, L. J., and Sobel, D. R., "Fuel-Cooled Thermal Management for Advanced Aeroengines," Journal of Engineering for Gas Turbines and Power, Vol. 126, April 2004, pp. 284-293.

[14] Kay, I. W., "Hydrocarbon-Fueled Ramjet/Scramjet Technology Program Phase II Extension Final Report," NASA CR-189659, July 1992.

[15] Kay, I. W., Peschke, W. T., and Guile, R. N., "Hydrocarbon-Fueled Scramjet Combustor Investigation," Journal of Propulsion and Power, Vol. 8, No. 2, March-April 1992, pp. 507-512.

[16] Yanovskii, L. S., Sapgir, G. B., Strokin, V. N., and Ivanov, V. F., "Endothermic Fuels: Some Aspects of Fuel Decomposition and Combustion at Air Flows," ISABE Paper 99-7067, Sept. 1999.
[17] Colket, M. B., and Spadaccini, L. J., "Scramjet Fuels Autoignition Study," Journal of Propulsion and Power, Vol. 17, No. 2, MarchApril 2001, pp. 315-323.

[18] Norris, R. B., "Freejet Test of the AFRL HySET Scramjet Engine Model at Mach 6.5 and 4.5," AIAA Paper 2001-3196, July 2001.

-[19] Fan, X. J., Yu, G., Li, J. G., Zhang, X. Y., and Sung, C. J., "Injection and Combustion of Vaporized Kerosene in a Supersonic Model Combustor," Journal of Propulsion and Power, Vol. 22, No. 1, 2006, pp. 103-110.

[20] Yu, G., Li, J. G., Zhang, X. Y., Chen, L. H., and Sung, C. J., "Investigation of Kerosene Combustion Characteristics with Pilot Hydrogen in Model Supersonic Combustors," Journal of Propulsion and Power, Vol. 17, No. 6, 2001, pp. 1263-1272.

[21] Dagaut, P., "On the Kinetics of Hydrocarbon Oxidation from Natural Gas to Kerosene and Diesel Fuel," Physical Chemistry and Chemical Physics, Vol. 4, No. 11, 2002, pp. 2079-2094.

[22] Ely, J. F., and Huber, M. L., "NIST Standard Reference Database 4NIST Thermophysical Properties of Hydrocarbon Mixtures," National Institute of Standards, Gaithersburg, MD, Feb. 1990.

[23] Yu, G., Li, J. G., Zhang, X. Y., Chen, L. H., Han, B., and Sung, C. J., "Experimental Investigation on Flameholding Mechanism and Combustion Performance in Hydrogen-Fueled Supersonic Combustors," Combustion Science and Technology, Vol. 174, No. 3, 2002, pp. 1-27.

R. Bowersox Associate Editor 
This article has been cited by:

1. Hojin Choi, Hyungju Lee, Kiyoung Hwang. 2013. Research Activities about Characteristics of Fuel Injection and Combustion Using Endothermic Fuel. Journal of the Korean Society of Propulsion Engineers 17:4, 73-80. [CrossRef]

2. Feng-Quan Zhong, Xue-Jun Fan, Jing Wang, Gong Yu, Jian-Guo Li. 2012. Characteristics of compressible flow of supercritical kerosene. Acta Mechanica Sinica 28:1, 8-13. [CrossRef]

3. Xunfeng Li, Xiulan Huai, Jun Cai, Fengquan Zhong, Xuejun Fan, Zhixiong Guo. 2011. Convective heat transfer characteristics of China RP-3 aviation kerosene at supercritical pressure. Applied Thermal Engineering 31:14-15, 2360-2366. [CrossRef]

4. Matthew J. DeWitt, Tim Edwards, Linda Shafer, David Brooks, Richard Striebich, Sean P. Bagley, Mary J. Wornat. 2011. Effect of Aviation Fuel Type on Pyrolytic Reactivity and Deposition Propensity under Supercritical Conditions. Industrial \& Engineering Chemistry Research 50:18, 10434-10451. [CrossRef]

5. Taichang Zhang, Xuejun Fan, Jing Wang, Jianguo Li, Gong YuPulsed Combustion of Hydrocarbon Fuels in a Supersonic Model Combustor . [Citation] [PDF] [PDF Plus]

6. Frank Lu, David Carter, Donald WilsonDevelopment of a Large Pulse Detonation Engine Demonstrator . [Citation] [PDF] [PDF Plus]

7. Fengquan Zhong, Xuejun Fan, Gong Yu, Jianguo Li, Chih-Jen Sung. 2011. Thermal Cracking and Heat Sink Capacity of Aviation Kerosene Under Supercritical Conditions. Journal of Thermophysics and Heat Transfer 25:3, 450-456. [Citation] [PDF] [PDF Plus]

8. Feng-Quan Zhong, Xue-Jun Fan, Gong Yu, Jian-Guo Li, Chih-Jen Sung. 2010. Performance of supersonic model combustors with staged injections of supercritical aviation kerosene. Acta Mechanica Sinica 26:5, 661-668. [CrossRef]

9. X. J. Fan, F. Q. Zhong, G. Yu, J. G. Li, C. J. Sung. 2009. Catalytic Cracking and Heat Sink Capacity of Aviation Kerosene Under Supercritical Conditions. Journal of Propulsion and Power 25:6, 1226-1232. [Citation] [PDF] [PDF Plus]

10. FengQuan Zhong, XueJun Fan, Gong Yu, JianGuo Li. 2009. Thermal cracking of aviation kerosene for scramjet applications. Science in China Series E: Technological Sciences 52:9, 2644-2652. [CrossRef]

11. Fengquan Zhong, Xuejun Fan, Jing Wang, Gong Yu, Jianguo Li, Chih-Jen SungThermal Cracking and Heat Sink Capacity of Aviation Kerosene Under Supercritical Conditions . [Citation] [PDF] [PDF Plus]

12. Fengquan Zhong, Xuejun Fan, Gong Yu, Jianguo Li, Chih-Jen Sung. 2009. Heat Transfer of Aviation Kerosene at Supercritical Conditions. Journal of Thermophysics and Heat Transfer 23:3, 543-550. [Citation] [PDF] [PDF Plus]

13. Fengquan Zhong, Xuejun Fan, Gong Yu, Jianguo Li, Xinian Lu, Chih-Jen SungHeat Transfer of Aviation Kerosene at Supercritical Conditions . [Citation] [PDF] [PDF Plus] 